\title{
INTEGRATION OF FIBER LASERS IN PROCESSES OF MINERAL RAW MATERIAL PROCESSING
}

\author{
Nina Leonenko ${ }^{1 *}$ \\ ${ }^{1}$ Mining Institute of Far eastern branch of Russian Academy of Sciences, Khabarovsk, Russia.
}

\begin{abstract}
Annotation. The application of laser technologies (LT) in the economy of the most developed countries. The possibility of using laser technologies for processing technogenic mineral raw materials is considered. The possibilities of integration of fiber-optic lasers into the processes of enrichment and processing of mineral raw materials are explored. The effects of interaction of laser radiation with mineral media - objects of Amur placer technogenic deposits containing submicron gold not extracted by modern gravitational methods are analyzed. The formation of selforganizing gold structures on the surface of a silicate matrix was established, general patterns of agglomeration and concentration of "nonextractable forms" of gold were revealed.
\end{abstract}

\section{Introduction}

The wide application and improvement of laser technologies (LT) in the economy of the most developed countries is a global trend of world development. The use of LT is crucial for increasing labor productivity and competitiveness of the national economy, expanding the opportunities for its integration into the world economic system. Laser processing of materials is one of those technologies that determine the current level of production in industrialized countries [1-4]. Distinctive features of the use of lasers in production - high quality of products, high process efficiency, saving of human and material resources, environmental cleanliness. A powerful impetus to the market sector, including laser processing of materials, gave fiber lasers, both small and high power. In 2012, four new companies entered the market - a supplier of such radiation sources, which are trying to compete with the recognized leader in this field - IPG Photonics Corporation. In general, laser technologies (LT) are developed in the EU, USA and Japan, and are reflected in Fig. 1. The countries of South-East Asia (Southeast Asia) are noticeably behind them, but even in these countries the volume of laser sales is about five times higher than in Russia. For example, in China, in Hubei province, which is the concentration of the optical industry in the country, the gross product of laser enterprises in $2005 \mathrm{y}$. exceeded 75 million \$. Laser technologies in the EU countries, in a more general sense - photonics, are viewed only as a locomotive of technological innovations. The photonics market in the world exceeds 150 billion euros, demonstrating a 14\% annual growth over the past 10 years.

\footnotetext{
${ }^{*}$ Corresponding author: leonenko@igd.khv.ru
} 


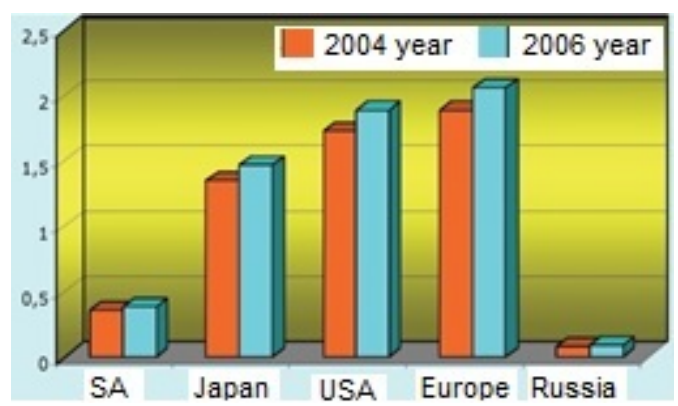

Fig. 1. Sales volume of technological lasers by region the world, bn $\$[5]$

According to the specialists' research of the general economic conjuncture, the growth rate of world production of laser systems and sources of laser radiation (LI) will remain at the level of $10-15 \%$. Lasers for processing materials sh at present ow the maximum dynamics of growth, both on the international and Russian markets. According to LaserMarketsResearch [5], from 2008 to 2016, the world market for lasers grew from 6.57 to 10.408 billion dollars. The share of lasers was $39 \%$, which used in the processing of materials in the global market in 2016 year: from \$ 213 million to \$ 1,304.8 million. Lasers for processing materials showed the greatest increase in this time. In 2016, they accounted for $41 \%$ of the total market. The table gives a comparison of various technological sources of laser radiation, which are currently used in the processing of materials. At the same time, from the analysis of the problems of processing and extraction of noble metal raw materials, it is known that, a sharp reduction in readily available gold reserves in ores and placers predetermined the search for new low-waste technologies for the extraction of gold and other precious metals from placer technogenic deposits. Involvement in the processing of man-made gold-bearing neo-formations accumulated over a long historical period of gold mining is highly relevant for the Far Eastern region. Such deposits, as a rule, have a high clay content in the sands. The metal is represented in the sludge fractions mainly in dispersed colloidal particles of lamellar or acicular form. The most of particles of gold, of lamellar and dendritic forms, is lost with tails, especially in classes of fineness less than $0.25 \mathrm{~mm}$ under gravity enrichment $[6,7]$. In mineral media, structural rearrangements occur under the influence of external energy flows on them, so that their state becomes far from thermodynamic equilibrium. Laser treatment of finely dispersed mineral media is one of the promising areas of such studies. This is because laser radiation creates high heat flux densities on both the surface and the volume of the material, sufficient heating, melting and evaporation days. In the work, the processes of interaction of laser radiation with dispersed mineral media have been experimentally investigated with the possible goal of integrating the modern powerful sources of laser radiation into the enrichment and complex processing of mineral raw materials. Among the non-traditional methods of energy impact are: electrochemical, microwave, electroimpulse, electrohydrodynamic, magnetic pulse processing, impact by a stream of accelerated electrons, super-powerful hyper-shock waves and powerful electromagnetic pulses [8]. Laser radiation makes it possible to provide high rates of local changes in temperature in the irradiated medium and temperature gradients, both in narrowly localized sections of surfaces and in the depth of materials due to low temperature conductivity. Such parameters can not be achieved with other methods of exposure. It is known that the properties of micron objects and nanoindivids differ from the properties of their macrohomologists. This is due to the dependence of the specific surface area of the particles on their size and, consequently, to incomparably higher structure perfection and surface effects. Such properties are thermal, electric, magnetic, high aggregative stability. For example, the melting point of the macrograin is $1064{ }^{\circ} \mathrm{C}$ gold, and the nanoindivide value of $4 \mathrm{~nm}$ is $427^{\circ} \mathrm{C}$. 
Table 1. Comparison of different types of lasers. Advantages of fiber lasers*

\begin{tabular}{|c|c|c|c|c|c|c|}
\hline Parameters & $\begin{array}{l}\text { Required for use } \\
\text { in industry }\end{array}$ & $\mathrm{CO}_{2}$ & $\begin{array}{l}\text { YAG-Nd } \\
\text { with lamp } \\
\text { pumping }\end{array}$ & $\begin{array}{l}\text { YAG-Nd } \\
\text { with diode } \\
\text { pumping }\end{array}$ & diode lasers & Fiber lasers \\
\hline Output power,кW & $1 \ldots 30$ & $1 \ldots 30$ & $1 \ldots .5$ & $1 \ldots 4$ & $1 \ldots 4$ & $1 \ldots 30$ \\
\hline Wavelength, mkm & as less as possible & 10,6 & 1,064 & $\begin{array}{c}1,064 \text { or } \\
1,03\end{array}$ & $0,8 \ldots 0,98$ & 1,07 \\
\hline Beam Parameter & & & & & & \\
\hline $\begin{array}{c}\text { Product, BPP, } \\
\text { mm x mrad }\end{array}$ & $<10$ & $3 \ldots 6$ & 22 & 22 & $>200$ & $1,3 \ldots 14$ \\
\hline Effectiveness, \% & $>20$ & $8 \ldots 10$ & $2 \ldots 3$ & $4 \ldots 6$ & $25 \ldots 30$ & $20 \ldots .25$ \\
\hline $\begin{array}{l}\text { Range of radiation } \\
\text { delivery by fiber, } \\
\text { m }\end{array}$ & $10 \ldots 300$ & absent & $20 \ldots 40$ & $20 \ldots 40$ & $10 \ldots .50$ & $10 . .300$ \\
\hline $\begin{array}{l}\text { Output Power } \\
\text { Stability }\end{array}$ & as high as possible & low & low & low & high & very high \\
\hline $\begin{array}{l}\text { Sensitivity to back } \\
\text { reflection }\end{array}$ & as low as possible & high & high & high & low & low \\
\hline Footprint, $\mathrm{m}^{2}$ & as less as possible & $10 \ldots 20$ & 11 & 9 & 4 & 0,5 \\
\hline $\begin{array}{l}\text { Cost of } \\
\text { installation, } \\
\text { relative unit. }\end{array}$ & as less as possible & 1 & 1 & 0,8 & 0,2 & $<0,05$ \\
\hline $\begin{array}{l}\text { Cost of operation, } \\
\text { relative unit }\end{array}$ & as less as possible & 0,5 & 1 & 0,6 & 0,2 & 0,13 \\
\hline $\begin{array}{l}\text { Cost of service, } \\
\text { relative unit }\end{array}$ & as less as possible & $1 \ldots 1,5$ & 1 & $4 \ldots 12$ & $4 \ldots 10$ & 0,1 \\
\hline $\begin{array}{l}\text { Periodicity of } \\
\text { replacement of } \\
\text { lamps or laser } \\
\text { diodes, hour. }\end{array}$ & as high as possible & - & $300 \ldots 500$ & $\begin{array}{c}2000 \ldots 500 \\
0\end{array}$ & \multicolumn{2}{|c|}{$2000 \ldots 5000>50000$} \\
\hline
\end{tabular}

\section{Materials and methods}

Experimental data were obtained on the ytterbium laser radiation sources LS-06 with a fiber transmission system. The coefficient of efficiency of such an installation is $30 \%$. On the ytterbium fiber-optic installation LS-06, it is possible to control both the radiation power from 0 to $600 \mathrm{~W}$. and the diameter of the local processing zone by placing the optical head 
over the material being processed. The operating mode of the radiation source is continuous, the modulation frequency of the output power is $5 \mathrm{kHz}$. The spectral width is $10 \mathrm{~nm}$. The wavelength $\lambda=1070 \mathrm{~nm}$. Natural gold-bearing dispersed images of mineral raw materials from high-clay technogenic objects of Far Eastern alluvial deposits with the particle size of $71 \mu \mathrm{m}, 40 \mu \mathrm{m}$ and $20 \mu \mathrm{m}$ were prepared for research. Gold-containing highclay aluminosilicate samples in loose form, with a layer thickness of $3 \mathrm{~mm}$, were placed on a special graphite substrate. The optical head was placed above the graphite substrate. It was possible to specify the parameters of defocused radiation. Laser radiation, passing through the ytterbium optical fiber fixed at the input of the optical head, and through the optical head placed vertically and rigidly on the tripod, fell on the samples under study. The substrate was moved at a speed of $1 \mathrm{~mm} / \mathrm{s}$. The diameter of the defocused radiation was chosen empirically and was $7 \mathrm{~mm}$.

The material composition of the directed change in the properties of the samples was studied with the help of electron and atomic force microscopy. The images were examined before and after laser treatment. As a result of laser action, the formation of enlarged gold of spherically agglomerated forms on an aluminosilicate matrix was recorded from microscopic analysis data.

Electron microscopic examination of the samples was carried out with a scanning electron microscope LEO EVO 40HV (Karl Zeiss, Germany) equipped with an energy dispersive analyzer INCA-ENERGY. The study of mineralogical objects using a secondary electron detector (SE detector) made it possible to obtain information on the topography of the samples. In addition to the detector of secondary electrons (SE detector), a backscattered electron detector (QBS detector) is used. With the aid of a QBS detector, phases with a higher average atomic number are more pronounced in contrast when the images are obtained than in phases with a lower atomic number. Since the difference in atomic weights of gold and minerals contained in the studied mineralogical objects is large, a more contrasting image is obtained, which makes it possible to visually reveal gold. The relief difference of agglomerated gold surfaces is revealed under the action of continuous energy laser radiation (LI). The sensitivity of the method is $\sim 0.1 \%$. The width of the electron beam is $\sim 20-30 \mathrm{~nm}$. The penetration depth of the electron beam is $\sim 1 \mu \mathrm{m}$. The local spectral analysis confirms the agglomeration of gold. When laser processing of goldbearing mineral raw materials, the character of fast-flowing processes is established, leading to the formation of various structural surfaces of gold, and general patterns of agglomeration and concentration of ultradispersed gold not extracted by gravitational methods are revealed. Figures 2-4 show images of optical, electron, and atomic force microscopy, respectively.
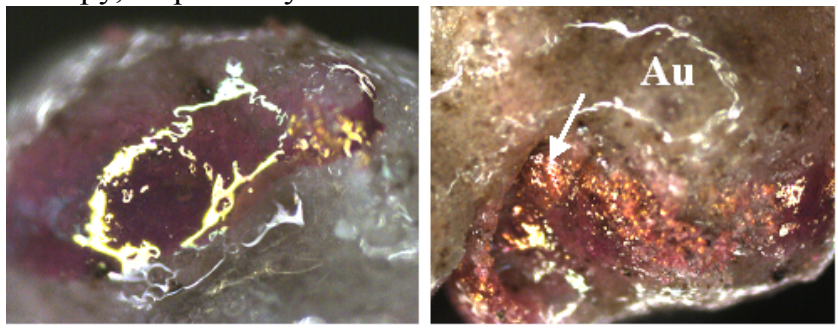

Fig. 2. Images of optical microscopy: micron forms of agglomerated gold, less than 1 $\mathrm{mm}$, on aluminosilicate spectra, samples from technogenic deposits

\section{Results and discussion}

It was shown in [9-11] that thermocapillary forces make the dominant contribution to the process of coarsening from nanoparticles to sizes of practical importance, up to hundreds of microns. Thus, under the influence of laser radiation, a thermal process of disintegration of 
the crystal lattice of the mineral occurs, followed by a rapid thermal process of recrystallization, defragmentation and sintering due to a laser exposure of a second duration. Due to this scenario, the chemical homogeneity of dispersed mineral objects increases.

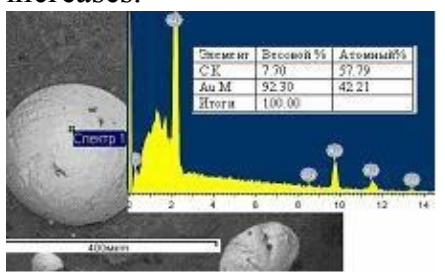

a $-1210^{x}$

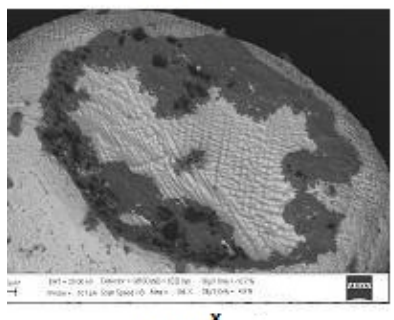

d - 194

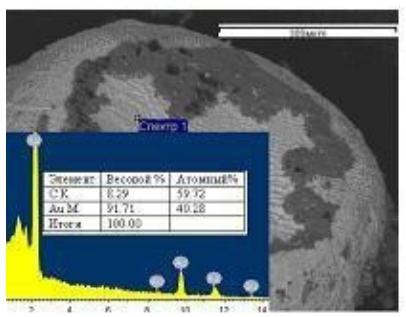

g

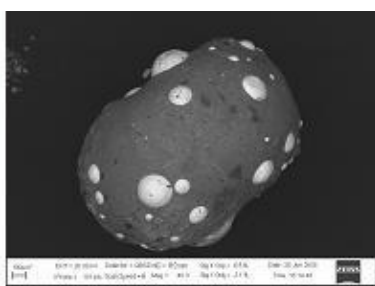

b $-40^{x}$

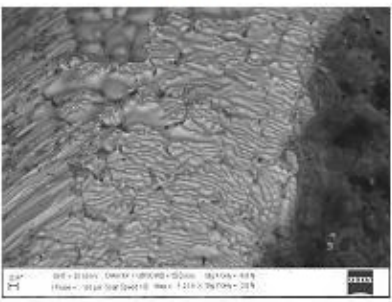

e $-1210^{x}$

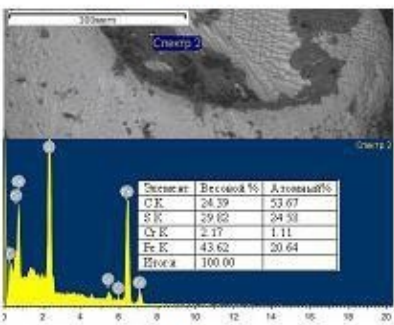

h

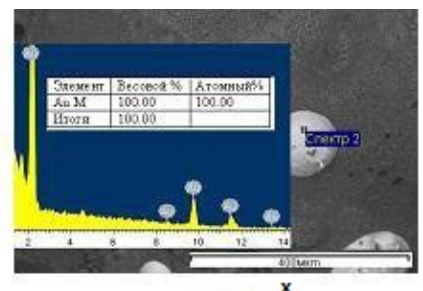

c $-1210^{x}$

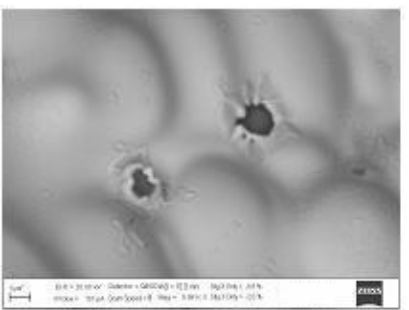

f $-5960^{x}$

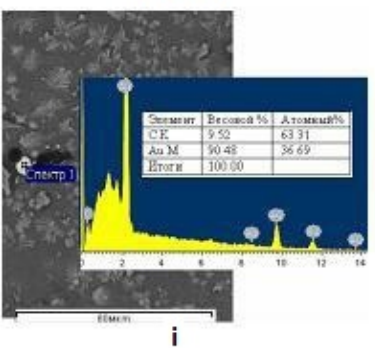

Fig. 3. Images of raster of agglomerated gold of spherical shape and the investigated areas of its surface after exposure to a continuous source of laser radiation LS-06. Risks: $400 \mathrm{mkm}$ - a, c; $300 \mathrm{mkm}$ - g, h; $100 \mathrm{mkm}$ - b; $60 \mathrm{mkm}$ - i; $20 \mathrm{mkm}$ - d; $2 \mathrm{mkm}$ e, $1 \mathrm{mkm}-\mathrm{f}$.

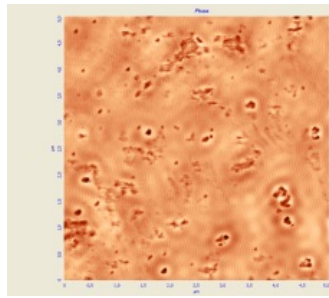

$\mathrm{a}$

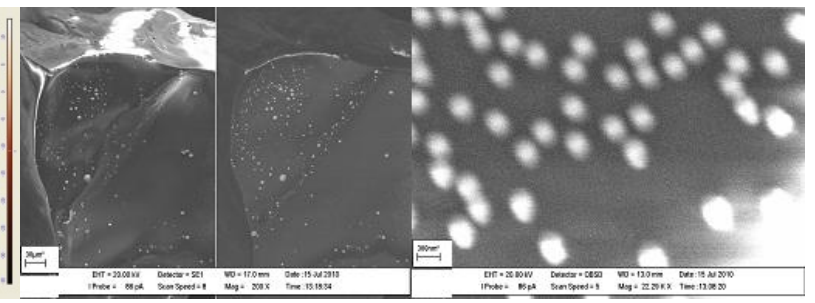

b

Fig. 4. Image of phase contrast of aluminosilicate cake with submicron gold after laser treatment, a - atomic force microscopy, scanning area $5 \times 5 \mu \mathrm{m}, \mathrm{b}$ - electron microscopy, nanometer size objects of gold $300 \mathrm{~nm}$.

Concentration and agglomeration of metals occurs under the action of laser radiation, in particular, gold in larger formations, which are distinguished by greater chemical purity than the original mineral associations. These studies are the scientific basis for developing 
new technologies for extracting submicron and nanometric forms of gold and other useful components. On this basis, a sufficiently effective and environmentally safe method of coarsening noble metal particles not extracted by traditional methods based on laser treatment of natural materials of anthropogenic character can be proposed [12]. It is possible that the use of modern laser radiation power sources with fiber-optic ytterbium energy transmission lines will make it possible to solve in the future purely practical tasks related to optimization of industrial technological processes of deep processing of manmade raw materials and extraction of valuable components. This testifies to the practical significance of the method.

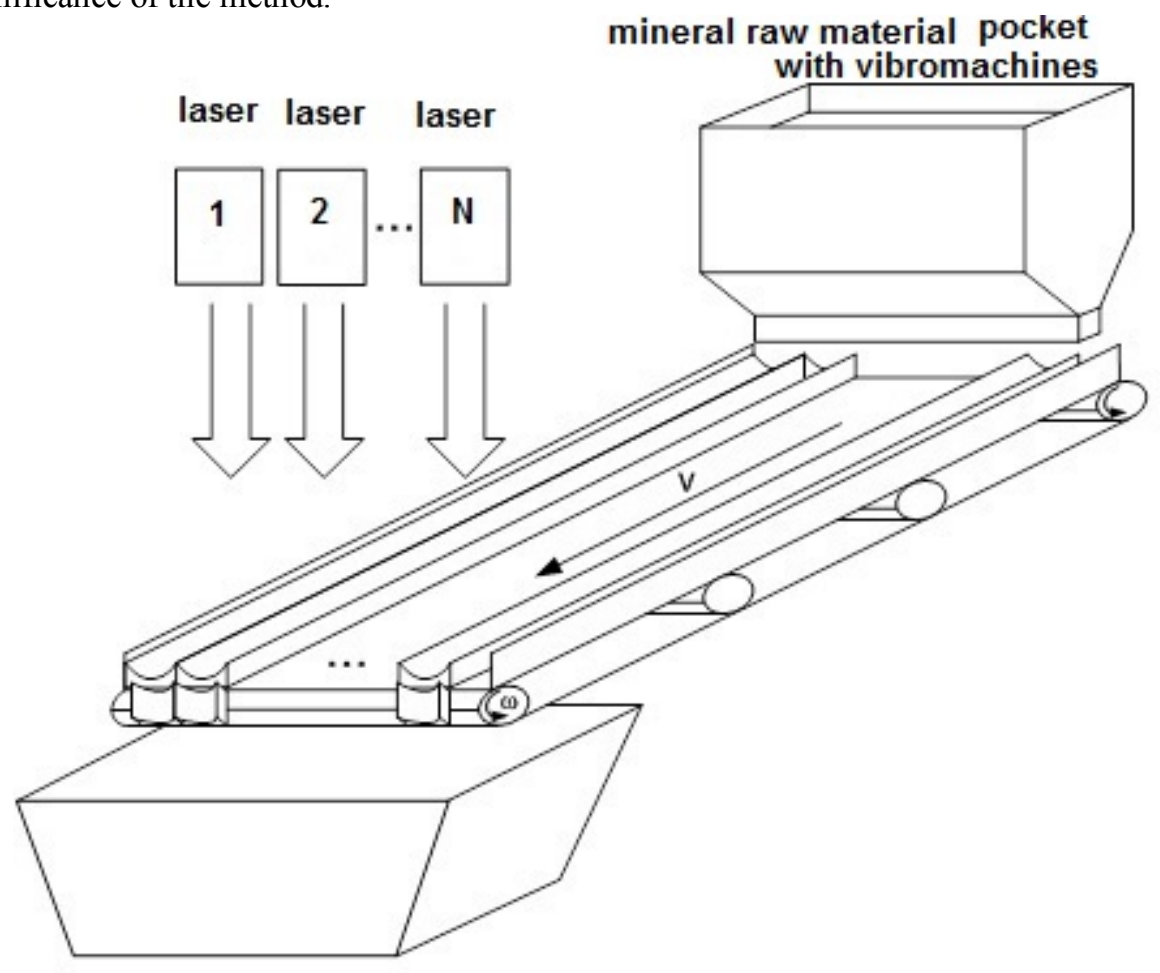

Fig. 5. Scheme of continuous flow technology for the extraction of submicron and ultradispersed gold particles on the basis of power laser fiber technology

\section{Conclusion}

The given examples of application of non-traditional technologies for extraction of ultradisperse and submicron gold particles allow us to consider that the solution of the problem of hard-to-extract forms of precious metals is possible. The method of laser treatment of gold-bearing high-argillaceous sands is approved. As a result, there is a redistribution of the substance with concentration and agglomeration of gold, which makes it possible to further integrate laser devices in the technology of mineral processing and processing of mineral raw materials. Figure 5 shows a patented scheme of continuous, ontime technology for the extraction of submicron and ultradispersed gold particles based on power laser fiber technology [13].

The article is implemented on a grant from the Ministry of Education and Science of the Khabarovsk Territory, Contract No. 115/2018 D. 


\section{References}

1. Official site of the innovative Holding "Schwabe" - [Electronic resource] URL: www.shvabe.com (date of the application 15.09.2017)

2. Official website of the group «IPG Photonics Corporation» - URL: http://www.ipgphotonics.com/ru (date of the application15.09.2017)

3. V. Kazakevich, S. Yaresko Trends in the development of the market of laser technologies for solving problems of laser processing of materials. Part 1. World Laser Market. "Izvestia of RAS Samara Scientific Center", 16. 266-275 (2014)/

4. V. Appolonov. Power Optics. Quantum Electronics. 44 (2), 102-121 (2014)

5. V. Appolonov. Lasers for industrial, scientific and ecological use. Springer Series in Optical Sciences, vol. 201. URL: https://doi.org/10.1007/978-3-319-33359-5_47.

6. Yu. Mamaev, V. Litvinsev, G. Ponomarchuk. Technogenic placers of precious metals of the Far Eastern region of Russia and their rational development, 309 (Moscow, 2010).

7. V. Litvinsev, T. Banshchikova, N. Leonenko, L. Shokina. Development of nonconventional technologies for recovery of refractory gold forms from mineral raw materials of production-induced deposits. Mineral processing, 3, 11-14 (2009).

8. V. Chanturia, I. Bunin. Non-traditional high-energy processes for disintegration and exposure of finely disseminated mineral complexes. Journal of mining science, 3, 311-330 (2007). DOI: 10.1007/s10913-007-0032-4.

9.A. Kuz'menko, N. Leonenko, V. Kharchenko, N. Kuz'menko, I. Silyutin, I. Khrapov. Termocapillary mechanism of laser-stimulated agglomeration of ultreadisperse and colloidal-ionicdold, Technical Physics Letters, 35(9), 837-840 (2009).

10. N. Leonenko, E. Vanina, E. Veselova, G. Kapustina. Nonlinear effects of laser radiation and physical model of laser agglomeration process. Russian Journal of General Chemistry, vol. 83, issue 2759-2764

(2013)

http://link.springer.com/article/10.1134/S1070363213130240.

11. N. Leonenko, E. Vanina, G. Kapustina, E. Veselova Study of Nonlinear Effect about Laser-induced Processes of Nanodispersed Gold in Mineral Association, Advanced Materials Research, 772, 355-358 (2013) doi:10.4028/www.scientific.net/AMR.772.355).

12. N. Leonenko, A. Kuz'menko, I. Silyutin et. al. RF Patent № 2413779 (April 7, 2010); 7 (2011).

13. A. Kuz'menko, I. Khrapov, N. Kuz'menko, N. Leonenko. RF Patent № 2541248 (July 17, 2012); 4 (2015). 